\title{
Transcriptome Profiling Reveals TGF- $\beta$ Signaling Involvement in Epileptogenesis
}

\author{
Luisa P. Cacheaux, ${ }^{1}$ Sebastian Ivens, ${ }^{3}$ Yaron David, ${ }^{4}$ Alexander J. Lakhter, ${ }^{4}$ Guy Bar-Klein, ${ }^{4}$ Michael Shapira, ${ }^{2}$ \\ Uwe Heinemann, ${ }^{3}$ Alon Friedman, ${ }^{3,4}$ and Daniela Kaufer ${ }^{1,2}$ \\ ${ }^{1}$ Helen Wills Neuroscience Institute and ${ }^{2}$ Department of Integrative Biology, University of California, Berkeley, Berkeley, California 94720-3140, ${ }^{3}$ Institute \\ of Neurophysiology, Charité University Medicine, 10117 Berlin, Germany, and ${ }^{4}$ Departments of Physiology and Neurosurgery, Zlotowski Center for \\ Neuroscience, Ben-Gurion University of the Negev, Beer-Sheva 84105, Israel
}

Brain injury may result in the development of epilepsy, one of the most common neurological disorders. We previously demonstrated that albumin is critical in the generation of epilepsy after blood-brain barrier (BBB) compromise. Here, we identify TGF- $\beta$ pathway activation as the underlying mechanism. We demonstrate that direct activation of the TGF- $\beta$ pathway by TGF- $\beta 1$ results in epileptiform activity similar to that after exposure to albumin. Coimmunoprecipitation revealed binding of albumin to TGF- $\beta$ receptor II, and Smad 2 phosphorylation confirmed downstream activation of this pathway. Transcriptome profiling demonstrated similar expression patterns after BBB breakdown, albumin, and TGF- $\beta 1$ exposure, including modulation of genes associated with the TGF- $\beta$ pathway, early astrocytic activation, inflammation, and reduced inhibitory transmission. Importantly, TGF- $\beta$ pathway blockers suppressed most albumininduced transcriptional changes and prevented the generation of epileptiform activity. Our present data identifies the TGF- $\beta$ pathway as a novel putative epileptogenic signaling cascade and therapeutic target for the prevention of injury-induced epilepsy.

\section{Introduction}

Epilepsy, affecting $0.5-2 \%$ of the population worldwide, is one of the most common neurological disorders. Focal neocortical epilepsy often develops after traumatic, ischemic, or infectious brain injury. Although the characteristic electrical activity in the epileptic cortex has been extensively studied, the mechanisms underlying the latent period preceding the occurrence of spontaneous epileptic seizures (epileptogenesis) are poorly understood. After injury, local compromise of blood-brain barrier (BBB) integrity is common (Tomkins et al., 2001; Neuwelt, 2004; Abbott et al., 2006; Oby and Janigro, 2006), as revealed by ultrastructural studies of animal and human epileptic tissue in multiple forms of epilepsy (Kasantikul et al., 1983; Cornford and Oldendorf, 1986; Cornford, 1999; Marchi et al., 2007; van Vliet et al., 2007), raising the possibility that vascular damage, and specifically BBB opening, may serve as a trigger event leading to epilepsy. This hypothesis has been confirmed by animal studies, in which opening of the BBB was sufficient to induce delayed epileptiform activity (Seiffert et al., 2004). Subsequent studies have shown that albumin, the most common serum protein, is sufficient to recapitulate the epileptiform activity induced by BBB disruption.

\footnotetext{
Received Jan. 21, 2009; revised May 15, 2009; accepted June 3, 2009.

This study was supported by the Citizens United for Research in Epilepsy foundation award (D.K. and A.F.), Sonderforschungsbereich TR3(C8) (A.F., U.H.), the Mary Elizabeth Rennie Epilepsy Foundation research grant (D.K.), the Israel Science Foundation (A.F.), and the United States-Israel Binational Science Foundation (A.F., D.K.). We thank Prof. John Ngai and Karen Vranizan for their help with the microarray design and analysis, and Aaron Friedman for comments on this manuscript.

Correspondence should be addressed to Prof. Daniela Kaufer, Department of Integrative Biology, 3060 Valley Life Sciences Building, University of California, Berkeley, Berkeley, CA 94720-3140. E-mail: danielak@berkeley.edu. DOI:10.1523/JNEUROSCI.0430-09.2009

Copyright $\odot 2009$ Society for Neuroscience $\quad$ 0270-6474/09/298927-09\$15.00/0
}

Furthermore, uptake of serum components such as albumin and IgGs, associated with BBB disruption, has been demonstrated in various cell populations. Albumin is taken up by astrocytes (Ivens et al., 2007; van Vliet et al., 2007), neurons (Marchi et al., 2007; van Vliet et al., 2007), and microglia although to a lesser extent (van Vliet et al., 2007), whereas IgG uptake has been found in neurons (Rigau et al., 2007). In rat lung endothelial cells, albumin endocytosis is mediated by transforming growth factor $\beta$ receptors (TGF- $\beta$ Rs), leading to phosphorylation of the proximate effector of the canonical TGF- $\beta$ signaling pathway, Smad2, and translocation of the activated Smad2/Smad4 complex to the nucleus (Siddiqui et al., 2004). TGF- $\beta$ Rs are also implicated in albumin uptake by astrocytes, as blocking TGF- $\beta$ Rs prevents albumin uptake and suppresses albumin-induced epileptiform activity (Ivens et al., 2007). This raises the possibility that albumin activation of the TGF- $\beta$ signaling pathway serves as the underlying mechanism; however, this hypothesis remains unconfirmed.

Here, we show that activation of the TGF- $\beta$ signaling pathway is sufficient to induce epileptiform activity. Furthermore, we show that global transcriptional cascades induced by TGF- $\beta 1$ or albumin exposure before the development of epileptiform activity (during the epileptogenesis window) are nearly identical and can be blocked by application of TGF- $\beta$ R blockers. Given the pleiotropic effects of the TGF- $\beta$ signaling pathway, these findings provide a plausible mechanism for epileptogenesis after brain injury and advocate a specific therapeutic target.

\section{Materials and Methods}

In vivo preparation. All experimental procedures were approved by the animal care and use ethical committees at Charité University Medicine, Berlin and Ben-Gurion University of the Negev, Beer-Sheva. The in vivo experiments were performed as described previously (Seiffert et al., 2004; 
Ivens et al., 2007). In short, adult male Wistar rats (120-250 g) were anesthetized and placed in a stereotactic cage, a $4 \mathrm{~mm}$ diameter bone window was drilled over the somatosensory cortex, and the dura was opened. The underlying cortex was then perfused with artificial CSF (aCSF; composition in mM: $129 \mathrm{NaCl}, 21 \mathrm{NaHCO}_{3}, 1.25 \mathrm{NaH}_{2} \mathrm{PO}_{4}, 1.8$ $\mathrm{MgSO}_{4} 1.6 \mathrm{CaCl}_{2}, 3 \mathrm{KCl}, 10$ glucose) supplemented with either deoxycholic acid (DOC; 2 mm; Sigma-Aldrich), bovine serum albumin (BSA; $0.1 \mathrm{~mm}$; Merck), corresponding to $25 \%$ of serum albumin concentration, or with TGF- $\beta 1$ (10 ng/ml; Peprotech) for $30 \mathrm{~min}$. Sham-operated animals (perfused with aCSF) served as controls. Only rats with no apparent injury to the cortical surface or bleeding from cortical vessels (as seen under the surgical microscope) at the end of the procedure were used.

To investigate transcriptional changes occurring during the epileptogenesis time window (before the development of epileptiform activity), animals were killed $7 / 8,24$, or $48 \mathrm{~h}$ after treatment. RNA isolated from these animals was used for microarray and quantitative real-time (qRT)PCR analyses described below. As robust changes in gene expression were observed after the $24 \mathrm{~h}$ treatments, a second set of animals including sham-operated controls and animals treated with BSA (0.1 mM) or BSA plus TGF- $\beta$ R blockers (TGF- $\beta$ RII antibody, $50 \mu \mathrm{g} / \mathrm{ml}$; Santa Cruz Biotechnology; SB431542, $100 \mu \mathrm{M}$, TGF- $\beta$ RI kinase activity inhibitor; Tocris Bioscience) were killed $24 \mathrm{~h}$ after treatment. RNA isolated from these animals was also used for microarray and qRT-PCR analyses. The last set of animals was treated with $0.1-0.2 \mathrm{~mm}$ BSA and killed 24 or $46-50 \mathrm{~h}$ after treatment for Smad2-P immunodetection.

In vitro slice preparation. Brain slices for the in vitro experiments were prepared using standard techniques (Pavlovsky et al., 2003; Seiffert et al., 2004; Ivens et al., 2007). Slices were transferred to a recording chamber where they were incubated in aCSF containing BSA $(0.1 \mathrm{~mm})$, TGF- $\beta 1$ $(10 \mathrm{ng} / \mathrm{ml}$ ), or artificial serum (aSERUM; composition based on aCSF with the following changes, composition in mM: $0.8 \mathrm{MgSO}_{4}, 1.3 \mathrm{CaCl}_{2}$, $5.7 \mathrm{KCl}, 1 \mathrm{~L}$-glutamine, $0.1 \mathrm{BSA})$. To block the activity of TGF- $\beta 1$, slices were incubated in aCSF containing SB431542 $(10 \mu \mathrm{M})$ before the addition of TGF- $\beta 1$ ( $10 \mathrm{ng} / \mathrm{ml})$. To block TGF- $\beta$ Rs, slices were incubated in aCSF containing SB431542 $(10 \mu \mathrm{M})$ and TGF- $\beta$ RII antibody $(10 \mu \mathrm{g} / \mathrm{ml})$ for 30 min followed by incubation in BSA in the presence of TGF- $\beta$ R blockers. For detection of epileptiform activity, field potentials were recorded 4-12 h after incubation in cortical layer IV using extracellular glass microelectrodes $(\sim 3 \mathrm{M} \Omega)$ in response to bipolar stimulation at the border of white and gray matter. The time of recording was chosen based on the occurrence of epileptiform activity $4-8 \mathrm{~h}$ after albumin exposure in the slice preparation (Ivens et al., 2007).

Albumin and TGF- $\beta$ RII coimmunoprecipitation. To prepare cortical lysates, brains were isolated from naive adult Wistar rats, dissected in cold saline solution, and lysed in radioimmunoprecipitation assay buffer. BSA $(3 \mu \mathrm{g})$ was added to lysates to approximately match the amount of precipitating anti-albumin antibodies. Immunoprecipitation was performed using the Catch and Release v2.0 Reversible Immunoprecipitation System (Millipore Bioscience Research Reagents) with the following modifications to the standard protocol: the starting amount of protein was increased to $1500 \mu \mathrm{g}$, and the incubation time with precipitating antibodies was increased to $90 \mathrm{~min}$. Lysate samples (positive or negative for albumin) were immunoprecipitated with an anti-TGF- $\beta$ RII antibody (Millipore Bioscience Research Reagents) or an anti-albumin antibody (Biogenesis).

The immunoprecipitated samples were separated with SDS-PAGE and transferred onto a nitrocellulose membrane. The membrane was stained with Ponceau S stain to confirm that the IP procedure was successful. It was then destained and blocked with 5\% BSA in standard TBS-T buffer overnight at $4^{\circ} \mathrm{C}$. TGF- $\beta$ RII was detected with a rabbit anti-TGF- $\beta$ RII antibody (Millipore Bioscience Research Reagents) and an alkaline phosphatase-conjugated donkey anti-rabbit IgG secondary antibody (Jackson ImmunoResearch Laboratories). Chemiluminescent detection was done using Lumi-Phos Western Blot Chemiluminescent Substrate (Pierce) and standard x-ray film according to the manufacturer's instructions.

Smad2-P Western blot analysis. Cortical lysate samples from shamoperated controls and animals treated with BSA were separated by SDSPAGE and transferred onto a nitrocellulose membrane. The membrane was blocked with $5 \%$ nonfat milk overnight at $4^{\circ} \mathrm{C}$, incubated with a rabbit polyclonal antibody against phospho-Smad2 (Millipore Bioscience Research Reagents) for $48 \mathrm{~h}$ at $4^{\circ} \mathrm{C}$, and incubated with a peroxidase-conjugated goat anti-rabbit IgG secondary antibody (Jackson ImmunoResearch Laboratories) for $2 \mathrm{~h}$ at room temperature.

Microarrays. Total RNA was isolated using the TRIzol reagent (Invitrogen) and prepared using the Affymetrix GeneChip one-cycle target labeling kit (Affymetrix). Biotinylated cRNA was fragmented and hybridized to the GeneChip Rat Genome 2302.0 Array according to company protocols (Affymetrix Technical Manual). Normalization of the array data was done using GC Robust Multi-Array Average analysis, which takes into account the GC content of the probe sequences (Wu et al., 2004). Functional annotation analysis was performed with the program Database for Annotation, Visualization, and Integrated Discovery (DAVID) 2008 (Dennis et al., 2003) (http://david.abcc.ncifcrf.gov). Unspecific (e.g., cellular process) and redundant terms (e.g., death and cell death) were removed, and the full lists are provided in supplemental Tables 1-8, available at www.jneurosci.org as supplemental material. The GenMAPP 2.0 program (Salomonis et al., 2007) (http://www. genmapp.org/) was used to visualize genes involved in TGF- $\beta$ signaling. For the time course analysis, one array was run for each treatment (DOC, BSA, TGF- $\beta 1$ ) for the following time points: $7 / 8,24$, and $48 \mathrm{~h}$. In addition, a sample from a sham-treated animal $(24 \mathrm{~h})$ was run and used to normalize the other arrays. Pairwise Pearson correlation coefficients for the three treatments were determined with Excel (Microsoft). Hierarchical clustering was performed with Gene Cluster and displayed with TreeView software (Eisen et al., 1998).

Arrays were then run for the second set of animals killed $24 \mathrm{~h}$ after treatment (sham, $n=2$; BSA, $n=3$; BSA plus TGF- $\beta$ R blockers, $n=4$ ). Significance analysis of microarrays (SAM) was performed with a false discovery rate (FDR) threshold of 9.2\%. A 1.5-fold change cutoff was also used to filter this list. Genes from this filtered list which demonstrated a $\log 2$ ratio difference $>0.5$ between the albumin and albumin plus blocker treatments were considered part of the attenuated response. The remaining genes were considered part of the unattenuated response. All microarray data are available at the Gene Expression Omnibus website (http://www.ncbi.nlm.nih.gov/geo) under accession number GSE12304.

Real-time RT-PCR. mRNA expression levels were determined by quantitative reverse transcriptase-PCR by real-time kinetic analysis with an iQ5 detection system (Bio-Rad). Real-time PCR data were analyzed using the PCR Miner program (Leonoudakis et al., 2008). 18S mRNA levels were used as internal controls for variations in sample preparation. Primer sequences are provided in supplemental Methods, available at www.jneurosci.org as supplemental material.

Statistical analyses. For the electrophysiological data, differences between treated and control slices were determined by the Mann-Whitney $U$ test for two independent samples or the $\chi^{2}$ test using SPSS 13.0. Linear regression analysis for the microarray data was performed with GraphPad Prism. PCR data were analyzed with an unpaired Student's $t$ test ( $p<0.05$ was considered significant) in Excel (Microsoft) or with the relative expression software tool (REST) (Pfaffl, 2001). REST determines significance of the group ratio results with a randomization test. $p<0.05$ was taken as the level of statistical significance.

\section{Results}

TGF- $\beta$ signaling is sufficient to induce epileptiform activity

To assess the hypothesis that activation of the TGF- $\beta$ signaling pathway is the mechanism underlying albumin-induced epileptogenesis, we activated this pathway directly by incubating neocortical slices with TGF- $\beta 1(10 \mathrm{ng} / \mathrm{ml})$ in aCSF and performed electrophysiological recordings. These recordings were compared with those of slices treated with aSERUM [a solution containing serum levels of electrolytes and $0.1 \mathrm{~mm}$ albumin, previously shown to induce epileptogenesis (Ivens et al., 2007)], albumin in aCSF, or aCSF (control). Spontaneous, prolonged, and hypersynchronous interictal-like activity was observed in slices treated with aSERUM after $6-10 \mathrm{~h}(n=6$ of 9 slices, three animals) but never in aCSF-treated slices (Fig. $1 B$ ). When albu- 
A

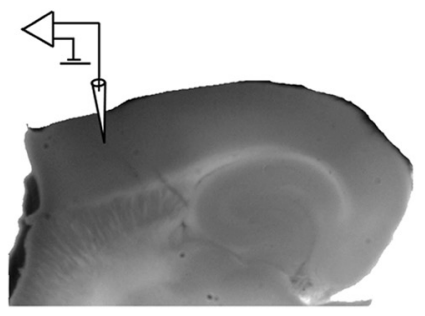

\section{C evoked activity}
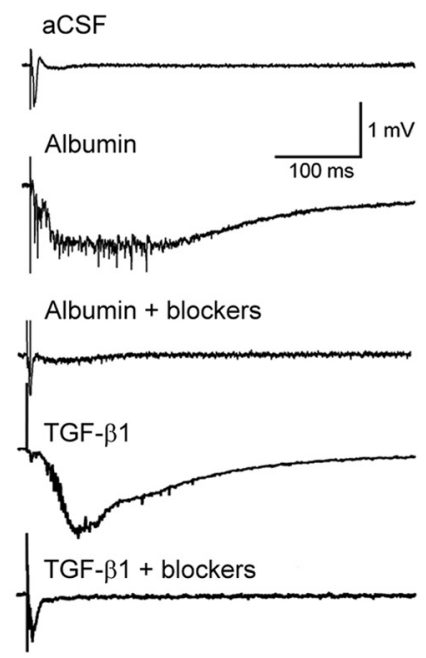

B

\section{spontaneous activity}
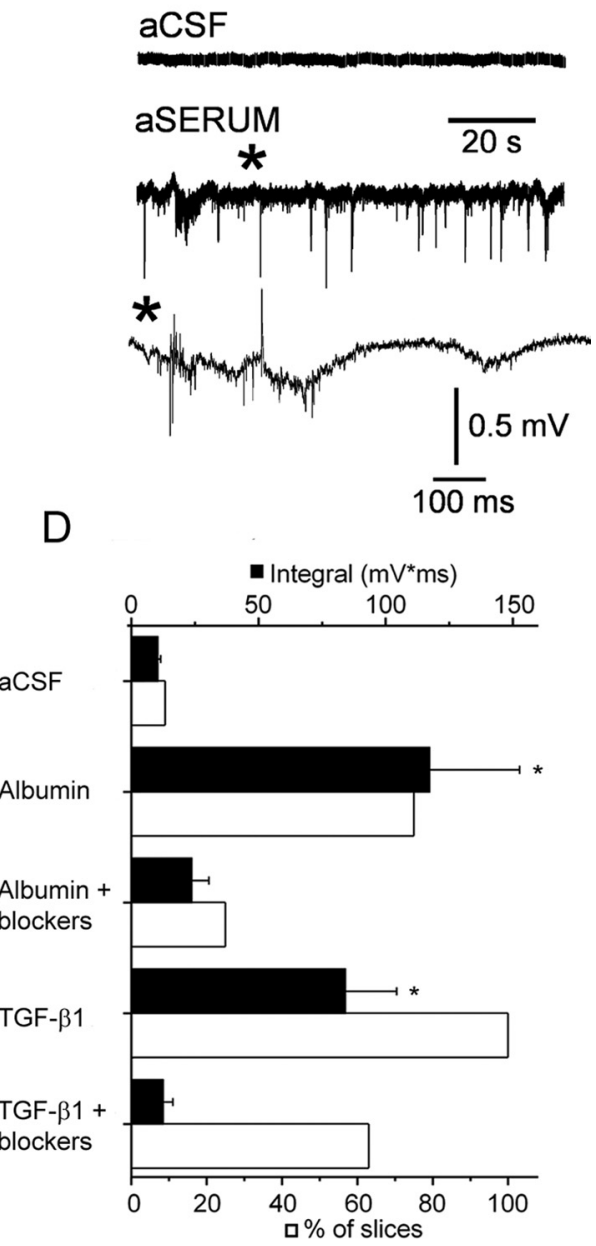

Figure 1. TGF- $\beta$ signaling induces epileptiform activity. $\boldsymbol{A}$, Photograph of a brain slice displaying electrode positioning. The stimulating electrode was placed at the white- gray matter border. $\boldsymbol{B}$, Extracellular recordings showing spontaneous interictallike epileptiform activity after treatment with aSERUM containing albumin. Asterisk refers to the region corresponding to the slower time scale shown in the lower trace. $\boldsymbol{C}$, Evoked responses from slices treated with aCSF, albumin, albumin plus TGF- $\beta$ receptor blockers, TGF- $\beta 1$, or TGF- $\beta 1$ plus TGF- $\beta$ receptor blockers. TGF- $\beta$ receptor blockers prevent epileptiform activity induced by albumin or TGF- $\beta 1$ treatment. $D$, Comparison of mean event integral (black bars) in the $50-500$ ms time range (after stimulation) shows a significant increase in the integral of the delayed epileptiform field potential in the albumin and TGF- $\beta 1$ treated slices but not in slices treated with TGF- $\beta$ receptor blockers. The white bars represent the percentage of slices with paroxysmal, epileptiform activity. Error bars indicate SEM. Asterisks indicate $p<0.05$.

min was added to the control aCSF solution, epileptiform activity was recorded only in response to stimulation of the white matter (Fig. 1C) ( $n=8$ of 12 slices, six animals). Importantly, epileptiform activity was also recorded after incubation in TGF- $\beta 1$, which is similar to that seen after treatment with aSERUM and albumin in aCSF (Fig. $1 C$ ) $(n=5$ of 5 slices, four animals; $n=7$ of 9 slices, three animals; and $n=8$ of 12 slices, six animals, respectively). Recordings were performed $4-12 \mathrm{~h}$ after treatment. Although treatment with either TGF- $\beta 1$ or albumin in aCSF resulted in the appearance of evoked epileptiform activity, only the altered electrolytic solution (i.e., aSERUM) resulted in spontaneous activity in the slice preparation. Importantly, when aSERUM was applied without albumin, neither spontaneous or evoked epileptiform activity was recorded. In all three cases (albumin, TGF- $\beta 1$, and aSERUM), the evoked epileptiform activity was all-or-none in nature, paroxysmal, prolonged, and propagating along the cortical slice, similar to that seen after BBB opening with bile salts (Seiffert et al., 2004; Ivens et al., 2007) and typical to that observed in acute models of epilepsy (Gutnick et al., 1982). No epileptiform activity was seen in the control aCSF-treated slices.

To further confirm that the TGF- $\beta 1$ induced epileptiform activity was dependent on the TGF- $\beta$ R-mediated pathway, we performed additional trials of the above experiments in the presence of two TGF- $\beta$ R blockers (SB431542 and antiTGF- $\beta$ RII antibody). TGF- $\beta$ R blockers prevented epileptiform activity induced by TGF- $\beta 1$ or albumin (Fig. $1 C$ ). The measured integral of the field potential (albu$\min , 117.2 \pm 35.4 \mathrm{mV}^{\star} \mathrm{ms}$; TGF- $\beta 1$, $84.1 \pm 20.1 \mathrm{mV}^{\star} \mathrm{ms}$ ) was significantly lower in slices treated with albumin or TGF- $\beta 1$ in the presence of TGF- $\beta$ R blockers (albumin and blockers: $23.7 \pm 6.9$ $\mathrm{mV}^{\star} \mathrm{ms}, n=20$ slices, four animals, $p=$ 0.001; TGF- $\beta 1$ and blockers: $12.5 \pm 3.9$ $\mathrm{mV}^{\star} \mathrm{ms}, n=8$ slices, four animals, $p=$ 0.005) (Fig. 1D).

\section{Albumin binds TGF- $\beta$ Rs and activates the TGF- $\boldsymbol{\beta}$ pathway}

To determine whether albumin binds to TGF- $\beta$ receptors, coimmunoprecipitation using antibodies against albumin or TGF$\beta$ RII was performed on cortical lysate samples (obtained from naive rats). An expected band corresponding to TGF- $\beta$ RII was detected in samples immunoprecipitated with the TGF- $\beta$ RII antibody. More importantly, this band was also detected in samples preincubated with albumin when immunoprecipitated with the albumin antibody and probed for TGF- $\beta$ RII (Fig. $2 A)$. These results reveal a direct interaction between albumin and TGF- $\beta$ RII. In the canonical TGF- $\beta$ signaling pathway, Smad 2 and/or 3 are phosphorylated after TGF- $\beta$ receptor activation and form a complex with Smad4, which then translocates into the nucleus and activates transcription (Beattie et al., 2002). To investigate whether albumin activates downstream components of the TGF- $\beta$ pathway, Smad2 phosphorylation levels in cortical lysates were assessed by Western blot, revealing an increase in Smad2 phosphorylation during the epileptogenic time window in animals exposed to albumin compared with sham-operated controls (Fig. $2 B$ ).

Similar transcriptional profiles follow BBB opening, albumin, and TGF- $\beta 1$ treatments

$\mathrm{BBB}$ opening or exposure to albumin in vivo (Ivens et al., 2007), as well as in vitro exposure of neocortical slices to albumin or TGF- $\beta 1$ (Fig. 1C), all result in the gradual development of hypersynchronous neuronal epileptiform activity. The delayed appearance of abnormal activity [5-7 h in vitro and $>4 \mathrm{~d}$ in vivo (Ivens et al., 2007)] suggests a transcription-mediated mechanism. In search of a common pathway and transcriptional activation pattern that underlie epileptogenesis after BBB opening, we per- 
A

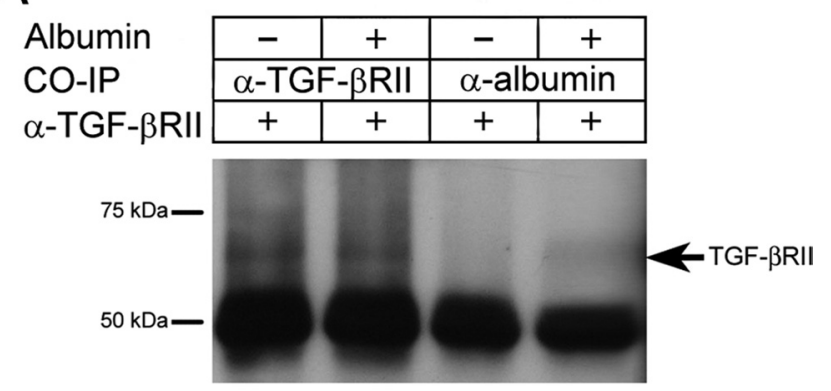

B

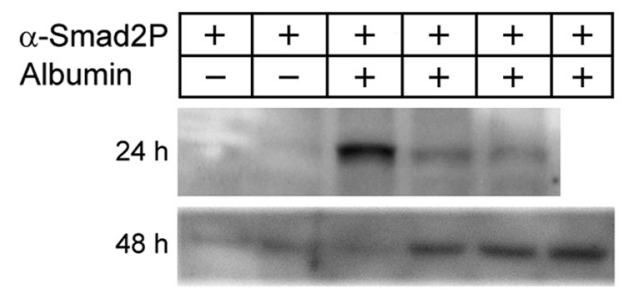

Figure 2. Albumin activates TGF- $\beta$ pathway. A, Albumin and TGF- $\beta$ RII immunoprecipitations. Samples treated or untreated with serum albumin were coimmunoprecipitated with antibodies directed against albumin or TGF- $\beta$ RII. All samples were then probed with an antiTGF- $\beta$ RII antibody. The band at $50 \mathrm{kDa}$ is the heavy chain of the precipitating antibody. $\boldsymbol{B}$, Western blot analysis of Smad2-P 24 and $48 \mathrm{~h}$ after albumin treatment. Each band represents a different animal ( $24 \mathrm{~h}$ : controls, $n=2$; albumin, $n=3 ; 48 \mathrm{~h}$ : controls, $n=2$; albumin, $n=4$ ).

formed transcriptome analysis using Affymetrix rat microarrays. RNA was extracted from cortical regions of rats treated with DOC (to induce BBB opening), albumin, or TGF- $\beta 1$ for various durations $(7 / 8,24,48 \mathrm{~h})$. These time points were chosen to evaluate changes in transcription occurring before the appearance of epileptiform activity. Control RNA was extracted from cortical regions excised from sham-operated animals. Hierarchical clustering analysis of these arrays showed that, overall, the three treatments resulted in strikingly similar gene expression profiles, as arrays representing similar time points clustered together regardless of the treatment (Fig. 3A). These similarities are exemplified in Figure $3 B$, which shows a high correlation between the expression profiles for the albumin and TGF- $\beta 1$ treatments at $24 \mathrm{~h}\left(r^{2}=0.75, p<0.0001\right)$.

To identify biological themes common to the three treatments, the gene list was filtered to include genes showing at least a 1.5-fold change in expression and a Pearson correlation coefficient $\geq 0.95$ for pairwise comparisons between all treatments (see Materials and Methods). Hierarchical clustering was performed, and the main clusters were used for gene ontology (GO) analysis with DAVID (Dennis et al., 2003). DAVID calculates the probability that particular GO annotations are overrepresented in a given gene list using a Fisher exact probability test. Molecular function and biological process GO terms with a $p$ value $<0.05$ containing at least three genes were considered significant. This analysis revealed major gene expression trends that occur in response to all three epileptogenic treatments (Fig. 3C). Early responses include genes involved in general stress-related cellular, metabolic, and intracellular signaling pathways; early responses persisting to later time points include inflammatory processes as well as genes involved in induction of cell cycle, differentiation, proliferation, and apoptosis; responses at middle to late time points include repression of synaptic transmission and ion transport genes (Fig. 3C) (for complete GO term annotation results, see supplemental Tables 1-4, available at www.jneurosci.org as supplemental material).

\section{Gene level expression profiles}

Selected GO term groups were chosen for further analysis of individual gene expression profiles (Fig. 4). The most dramatic change observed in all treatments across all time points was the early and persistent upregulation of genes associated with immune response activation (Fig. 4A,B). Inflammatory genes included NF- $\kappa$ B pathway-related genes, cytokines, and chemokines (Il6, Ccl2, Ccl7), transcription factor Stat3, the pattern recognition receptor $C D 14$, and extracellular matrix proteins (Fn1 and Spp1) (Fig. 4A). Activation of the complement pathway was also prominent (Fig. $4 B$ ) and included C1 subcomponents (C1qa, $C 1 q b, C 1 q g$ ), the associated protease C1s, Masp1, and C2. A significant neuronal response was prominent in the middle-late time points and included downregulation of genes associated with GABAergic (inhibitory) neurotransmission (including the $\mathrm{GABA}_{\mathrm{A}}$ receptor subunits, Gabra4, Gabrd, Gabrg1, and Gabrb2, as well as glutamic acid decarboxylase (Gad67) (Fig. 4C) and modulation of genes associated with glutamatergic (excitatory) neurotransmission (including upregulation of the ionotropic glutamate receptor subunits, GluR $\delta 2$ and $G l u R 1$ and downregulation of the NMDA receptor subunits, $N R 2 B, N R 2 A$, and NR2C and the metabotropic glutamate receptor, $m G l u R 7$ ) (Fig. 4D). Furthermore, a variety of voltage-gated ion channels, including calcium, sodium, chloride, and potassium channels, were affected by all three epileptogenic treatments (Fig. $4 E$ ), including a noteworthy downregulation of voltage-gated (Kv7.3 and $K v 8.1)$ and inward-rectifying (Kir3.1) potassium channels. We also found significant modulation of glial-specific genes beginning at the early time point (Fig. $4 F$ ): the cytoskeletal proteins GFAP and vimentin (Vim), and several calcium-binding proteins (S100a6, S100a10, s100a11), were all upregulated while gap junction connexins 30 and 43 (Cx30 and $C \times 43$ ) and the inward-rectifying potassium channel Kir4.1 were downregulated. Microarraybased gene expression measurements for selected genes were further verified using quantitative real-time PCR. Expression patterns were similar, although the magnitude of the fold changes sometimes differed (supplemental Fig. 1, available at www. jneurosci.org as supplemental material).

\section{TGF- $\beta$ pathway activation underlies epileptogenic transcriptional response}

Given the high correlation between expression profiles after the three epileptogenic treatments, combined with the biochemical evidence that albumin binds to TGF- $\beta$ receptors and the physiological evidence that TGF- $\beta 1$ induces evoked epileptiform activity, we assessed the extent to which each treatment activates transcription of genes known to be associated with the TGF- $\beta$ signaling pathway using GenMAPP (Salomonis et al., 2007). Forty-three percent of genes analyzed in the TGF- $\beta$ signaling pathway were modulated by both treatment with albumin and TGF- $\beta 1$. Genes which showed at least a 1.5 -fold change in expression after albumin or TGF- $\beta 1$ treatment are highlighted in Figure 5 . Importantly, $86 \%$ of genes modulated by TGF- $\beta 1$ treatment are also modulated after albumin treatment, indicating a high degree of overlap. To check the specificity of this pathway activation, additional pathways were analyzed. Indeed, there was still a high degree of overlap, but the percentage of genes modulated by both albumin and TGF- $\beta 1$ treatments was much lower. For example, for the androgen receptor and $\alpha 6-\beta 4$ integrin sig- 
A

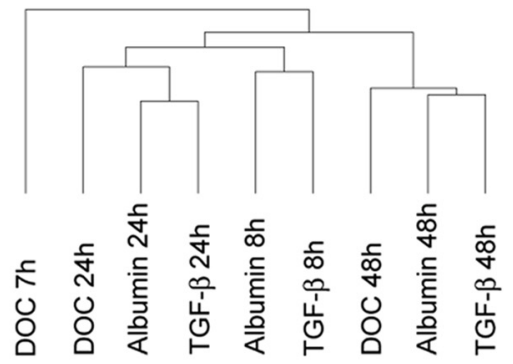

B

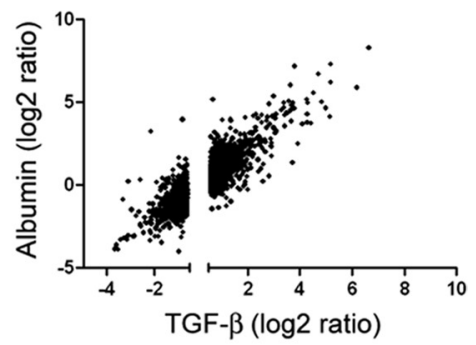

C

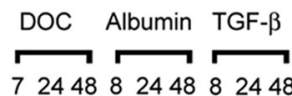

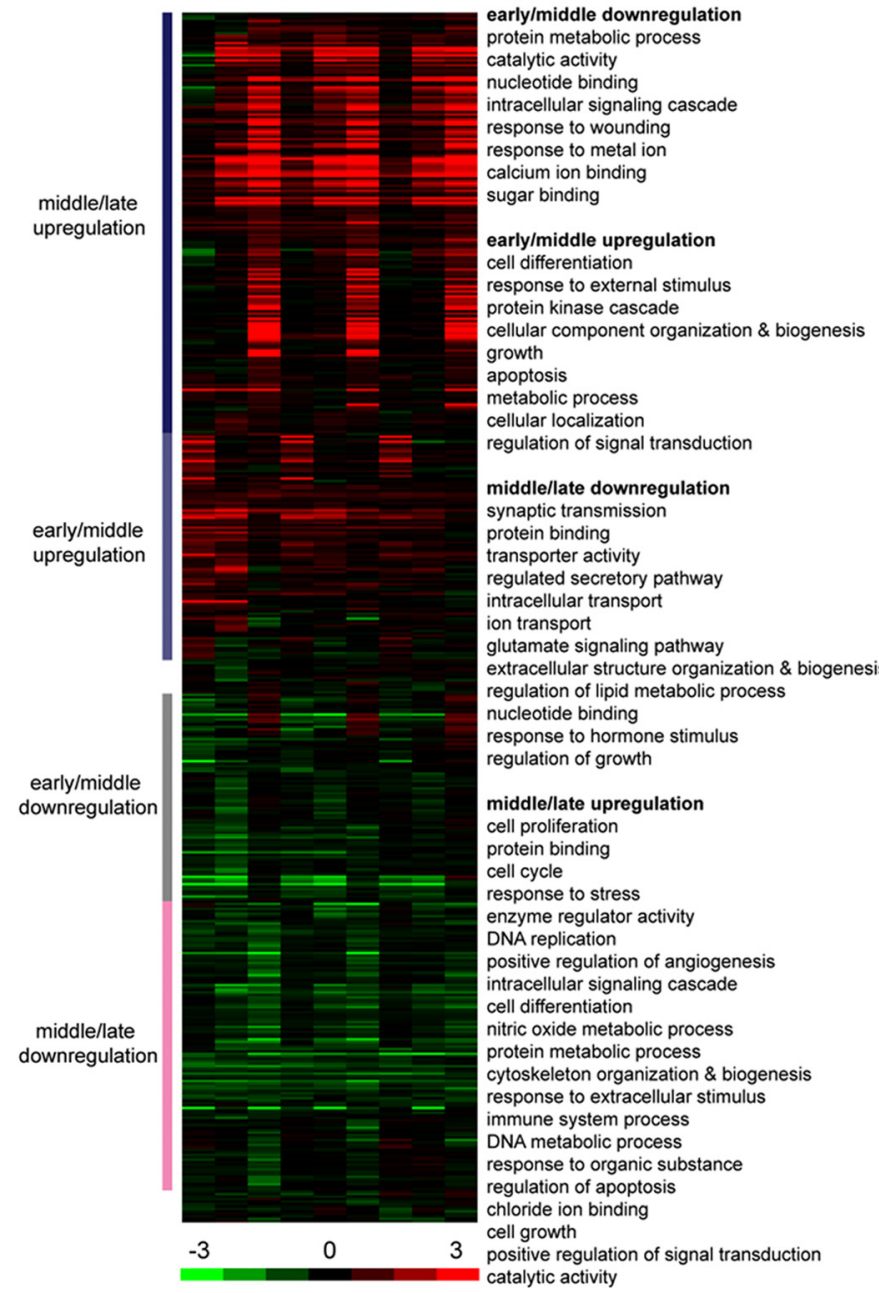

\# genes $\quad \% \quad \mathrm{p}$-value

$\begin{array}{lll}21 & 23.1 & 4.4 \mathrm{E}-04 \\ 28 & 30.8 & 1.3 \mathrm{E}-03\end{array}$

$\begin{array}{lll}28 & 30.8 & 1.3 \mathrm{E}-03 \\ 13 & 14.3 & 1.5 \mathrm{E}-02\end{array}$

$10 \quad 11.0 \quad 1.6 \mathrm{E}-02$

$\begin{array}{lll}6 & 6.6 & 1.6 \mathrm{E}-02 \\ 3 & 3.3 & 2.0 \mathrm{E}-02\end{array}$

$\begin{array}{lll}7 & 7.7 & 3.5 \mathrm{E}-02\end{array}$

$\begin{array}{ll}7.4 & 3.9 \mathrm{E}-02 \\ & \end{array}$

$\begin{array}{lll}8 & 10.5 & 4.2 \mathrm{E}-03 \\ 6 & 7.9 & 4.9 \mathrm{E}-03\end{array}$

$15 \quad 19.7 \quad 5.5 \mathrm{E}-03$

$6.6 \quad 1.1 \mathrm{E}-02$

$9.2 \quad 1.4 \mathrm{E}-02$

$36.8 \quad 3.4 \mathrm{E}-02$

$\begin{array}{ll}9.2 & 3.8 \mathrm{E}-02 \\ 6.6 & 4.6 \mathrm{E}-02\end{array}$

$13-10.7 \quad 1.7 \mathrm{E}-07$

$33.9 \quad 1.0 \mathrm{E}-04$

3.0E-04

1.2E-03

3. $\mathrm{OE}-03$

6.1E-03

$6.8 \mathrm{E}-03$

$1.0 \mathrm{E}-02$

$1.6 \mathrm{E}-02$

2.7E-02

$4.0 \mathrm{E}-02$

$4.3 \mathrm{E}-02$

$\begin{array}{ccc}21 & 12.1 & 5.2 \mathrm{E}-06 \\ 64 & 36.8 & 9.3 \mathrm{E}-06 \\ 17 & 9.8 & 1.1 \mathrm{E}-05 \\ 23 & 13.2 & 7.9 \mathrm{E}-05 \\ 14 & 8.1 & 1.8 \mathrm{E}-03 \\ 7 & 4.0 & 4.2 \mathrm{E}-03 \\ 3 & 1.7 & 7.4 \mathrm{E}-03 \\ 21 & 12.1 & 7.5 \mathrm{E}-03 \\ 24 & 13.8 & 9.8 \mathrm{E}-03 \\ 3 & 1.7 & 1.3 \mathrm{E}-02 \\ 39 & 22.4 & 1.6 \mathrm{E}-02 \\ 10 & 5.8 & 1.9 \mathrm{E}-02 \\ 5 & 2.9 & 2.2 \mathrm{E}-02 \\ 13 & 7.5 & 2.6 \mathrm{E}-02 \\ 11 & 6.3 & 2.8 \mathrm{E}-02 \\ 5 & 2.9 & 3.4 \mathrm{E}-02 \\ 10 & 5.8 & 4.1 \mathrm{E}-02 \\ 3 & 1.7 & 4.2 \mathrm{E}-02 \\ 5 & 2.9 & 4.4 \mathrm{E}-02 \\ 5 & 2.9 & 4.5 \mathrm{E}-02 \\ 49 & 28.2 & 4.8 \mathrm{E}-02\end{array}$

$14 \quad 18.4 \quad 4.2 \mathrm{E}-04$

Figure 3. Genome-wide transcriptional analysis after epileptogenic treatments. A, Hierarchical clustering of arrays corresponding to $7 / 8,24$, and $48 \mathrm{~h}$ after DOC, albumin, and TGF- $\beta 1$ treatments. Note how arrays cluster together for each time point across all treatments. Genes showing at least a 1.5 -fold change in expression were included. $\boldsymbol{B}$, Linear regression analysis between TGF- $\beta 1$ and albumin treatments at $24 \mathrm{~h}$. Only genes with a fold change equal to or $>1.5$ for the TGF- $\beta 1$ treatment were included. C, Hierarchical cluster analysis of genes showing correlation $(>0.95)$ between all treatments. Selected clusters were annotated with DAVID to reveal biological themes common to all treatments. Color bar indicates range of $\log _{2}$ ratios.

naling pathways, only 21.7 and $24 \%$ of genes analyzed were modulated by both treatments.

The above evidence indicates that TGF- $\beta$ signaling is a key mediator of albumin-induced epileptogenesis. To determine if the global transcriptional response seen after albumin treatment is dependent on activation of the TGF- $\beta$ signaling pathway, we performed an additional set of microarray expression profiles using rats treated with albumin in the absence $(n=3)$ or presence of TGF- $\beta$ RI and II blockers $(n=4$, TGF- $\beta$ R1 kinase activity

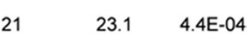

inhibitor SB431542 and anti-TGF- $\beta$ RII antibody) and killed $24 \mathrm{~h}$ after treatment. Although some changes in gene expression resulting from albumin treatment were still present after the blocker treatment, the majority of these changes were absent or attenuated after TGF- $\beta$ pathway blocker treatment (Fig. 6A), confirming dependence of the albumin-induced transcriptional response on TGF- $\beta$ signaling.

Gene ontology analysis was then used to reveal which biological processes were blocked after TGF- $\beta$ pathway blocker treatment (Fig. 6A) (for complete GO term annotation results, see supplemental Tables 5-8, available at www.jneurosci. org as supplemental material). Genes in the TGF- $\beta$ signaling GO term demonstrated a dramatic suppression of the albumin-induced expression changes in the presence of TGF- $\beta$ signaling blockers (Fig. $6 B$ ). In addition, TGF- $\beta$ pathway blocker treatment prevented the albumininduced modulation of genes involved in neuronal processes, immune response, and ion and cellular transport (Fig. 6B). Several prominent signaling pathways including the NF- $\kappa$ B cascade, Jak-Stat cascade, and MAPKKK cascade were upregulated after albumin treatment but did not show a similar upregulation after albumin treatment in the presence of TGF- $\beta$ pathway blockers. Quantitative real-time PCR was also performed with these samples to confirm the microarray results (Fig. $6 C$ ). Indeed, TGF- $\beta$ pathway blocker treatment completely blocked expression changes after albumin exposure for Stat 3 and Glt-1 and partially blocked changes for $C x 43$ and GFAP.

\section{Discussion}

$\mathrm{BBB}$ breakdown is a hallmark of vascular injury in the brain and is observed in numerous neurological diseases including traumatic brain injury, stroke, and neurodegenerative diseases (Neuwelt, 2004; Abbott et al., 2006; Oby and Janigro, 2006; Zlokovic, 2008).

Compromise of the $\mathrm{BBB}$ is triggered by preceding processes that in turn cause vascular injury. For example, perivascular astrocytes or perivascular microglia could be activated by an initial precipitating event (trauma or ischemia) and cause vascular injury leading to serum albumin extravasation into the brain parenchyma. We have previously shown development of cortical dysfunction-specifically, hypersynchronous neuronal activity after BBB opening or exposure to serum albumin (Seiffert et al., 2004; Ivens et al., 2007). Cortical dysfunction was followed by reduced dendritic branching and neuronal loss several weeks after either treatment (Ivens et al., 2007).

In this study, we now extend these findings to include the 
appearance of spontaneous, prolonged, and hypersynchronous interictal-like activity after treatment with albumin in a solution containing serum levels of electrolytes (aSERUM). We did not observe spontaneous activity when slices were treated with albumin or TGF- $\beta$ in aCSF, probably attributable to the generally low excitability and lack of spontaneous activity of the deafferented slice preparation (Connors et al., 1982; Gutnick et al., 1982). The changes in electrolyte concentrations in the aSERUM solution (e.g., higher $\mathrm{K}^{+}$, lower $\mathrm{Mg}^{2+}$ and $\mathrm{Ca}^{2+}$ ) are probably sufficient to increase neuronal excitability such that the epileptiform activity, which characterizes the network during activation, appears spontaneously. We have previously shown that spontaneous activity is rarely evoked in slices treated with albumin in aCSF ( $\sim 10 \%$ of slices) [see also Seiffert et al. (2004)]. Importantly, spontaneous recurrent seizures followed by secondary generalization were also observed in some animals treated with albumin (Ivens et al., 2007). These observations combined with the appearance of epileptiform activity after albumin treatment in vitro likely reflect abnormal network epileptic activity in vivo.

Since serum albumin is sufficient to induce epileptic-like activity, our initial hypothesis was that albumin enters the normally inaccessible CNS environment, binds to TGF- $\beta$ receptors, and causes a cascade of events culminating in epileptiform activity. Here, we report similar development of epileptiform activity after exposure to TGF- $\beta 1$, demonstrating the importance of TGF- $\beta$ pathway activation in this injury model. We further show that albumin binds TGF$\beta$ RII and induces the phosphorylation of Smad2. Given the latent period before the appearance of epileptiform activity (i.e., epileptogenesis), we hypothesized that BBB breakdown, albumin, and TGF- $\beta 1$ share a common mechanism, specifically a transcriptional mechanism involving the TGF- $\beta$ pathway. Indeed, clustering and gene ontology analysis revealed striking similarities across the three treatments. The most prominent finding from our microarray results is the identification of a key role for TGF- $\beta$ signaling, with activation of TGF- $\beta$ related genes seen in response to TGF$\beta 1$, albumin, and BBB breakdown. Blocking TGF- $\beta$ signaling prevented the majority of the albumin-induced transcriptional responses, allowing us to narrow our gene list and identify the genes that are most relevant to epileptogenesis under these conditions. Furthermore,
A

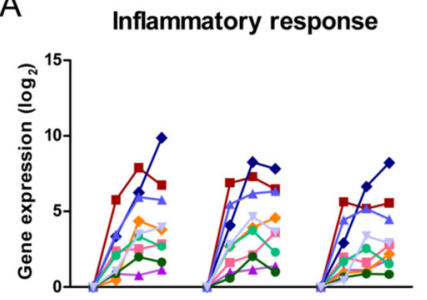

C

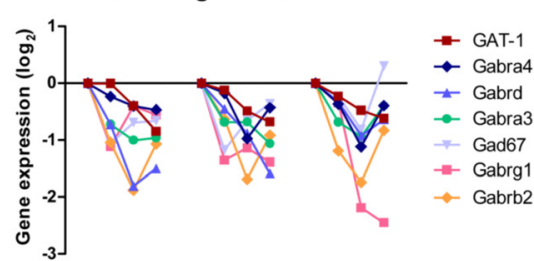

E
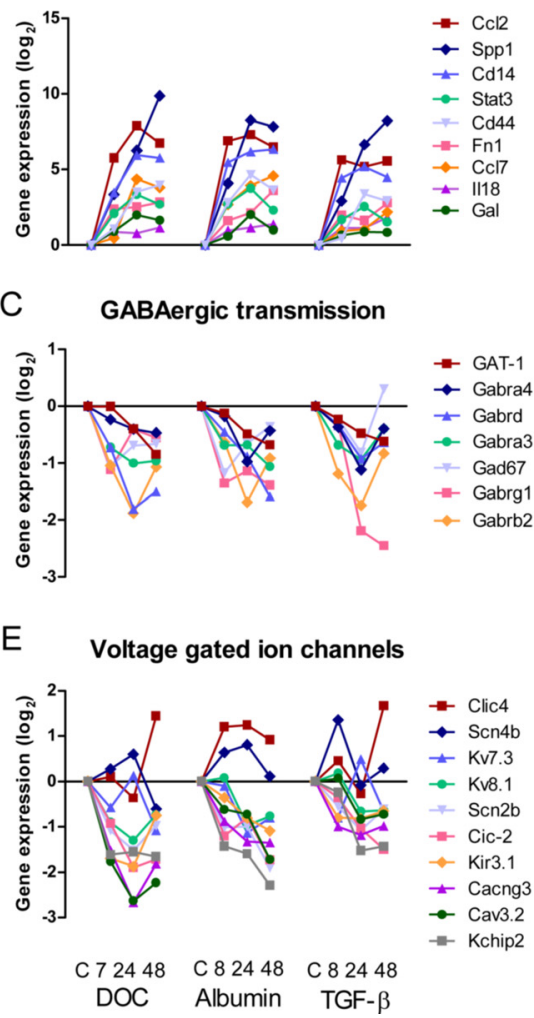

B

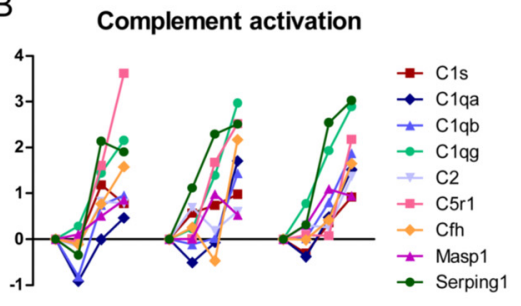

D

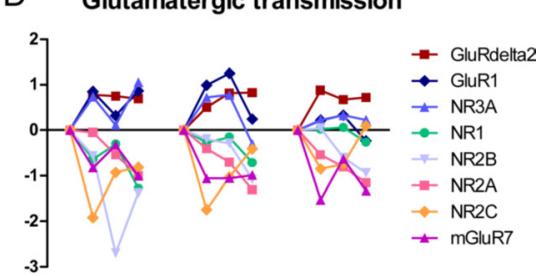

$\mathrm{F}$

Astrocytic related genes

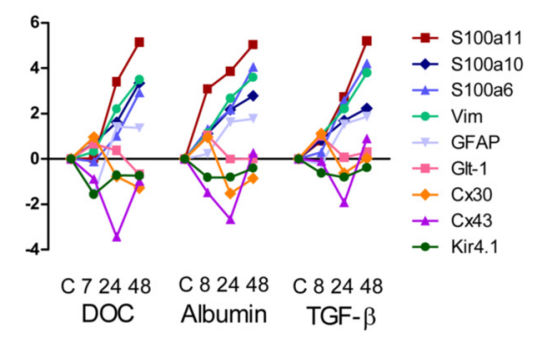

Figure 4. Gene ontology annotation analysis. $\boldsymbol{A}-\boldsymbol{F}, \log _{2}$ ratios for selected genes from $G 0$ annotation analysis involved in inflammation $(\boldsymbol{A})$, complement activation $(\boldsymbol{B})$, GABAergic transmission $(\boldsymbol{C})$, glutamatergic transmission $(\boldsymbol{D})$, voltage-gated ion channels $(\boldsymbol{E})$, and astrocytes $(\boldsymbol{F})$. Numbers below data points correspond to the various treatments $(7 / 8,24$, and $48 \mathrm{~h})$.

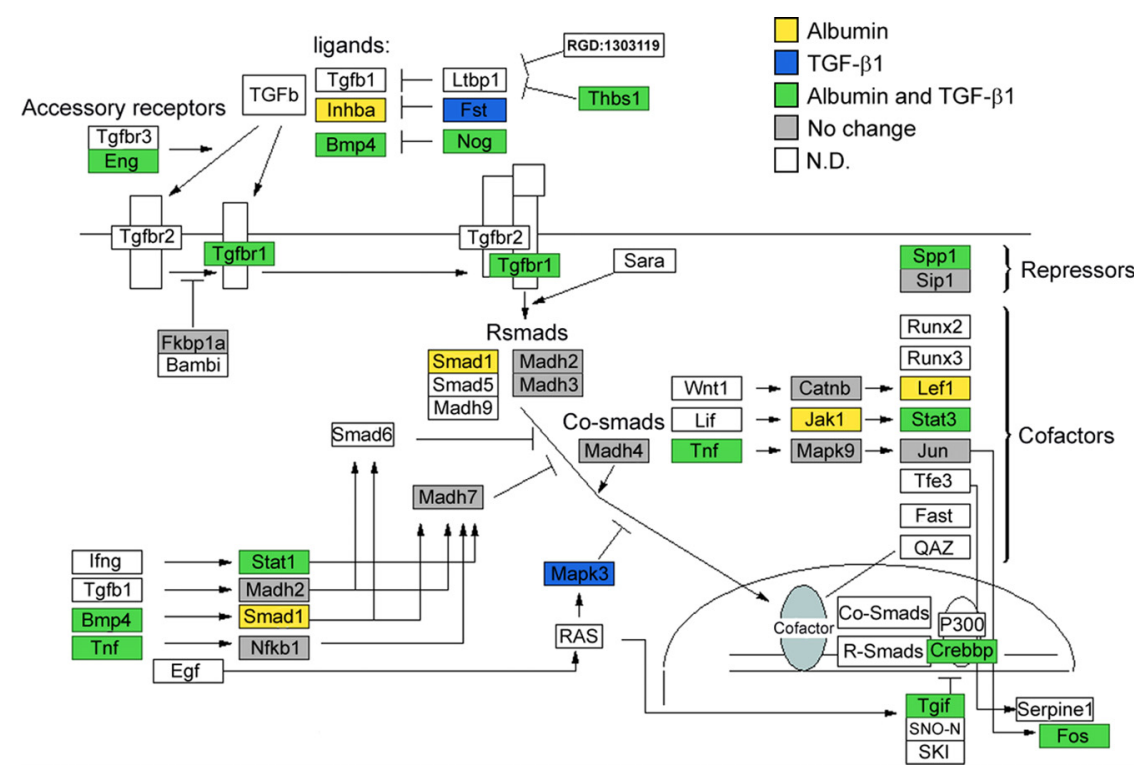

Figure 5. Albumin alters TGF- $\beta$ pathway gene expression. TGF- $\beta$ pathway map generated with GENMAPP software illustrating significant changes ( $>1.5$ or $<-1.5$-fold change) in gene expression after albumin treatment compared with TGF- $\beta 1$ treatment. Yellow-labeled genes represent genes up or downregulated after albumin treatment, blue-labeled genes represent genes up or downregulated after TGF- $\beta 1$ treatment, and green-labeled genes represent genes up or downregulated after both treatments. Gene pathway map created by Nurit Gal and Manny Ramirez, Copyright 2002, Gladstone Institute.

application of TGF- $\beta$ R blockers suppressed the development of epileptiform neuronal activity after albumin or TGF- $\beta 1$ treatment, highlighting this pathway as a novel therapeutic target. 
A

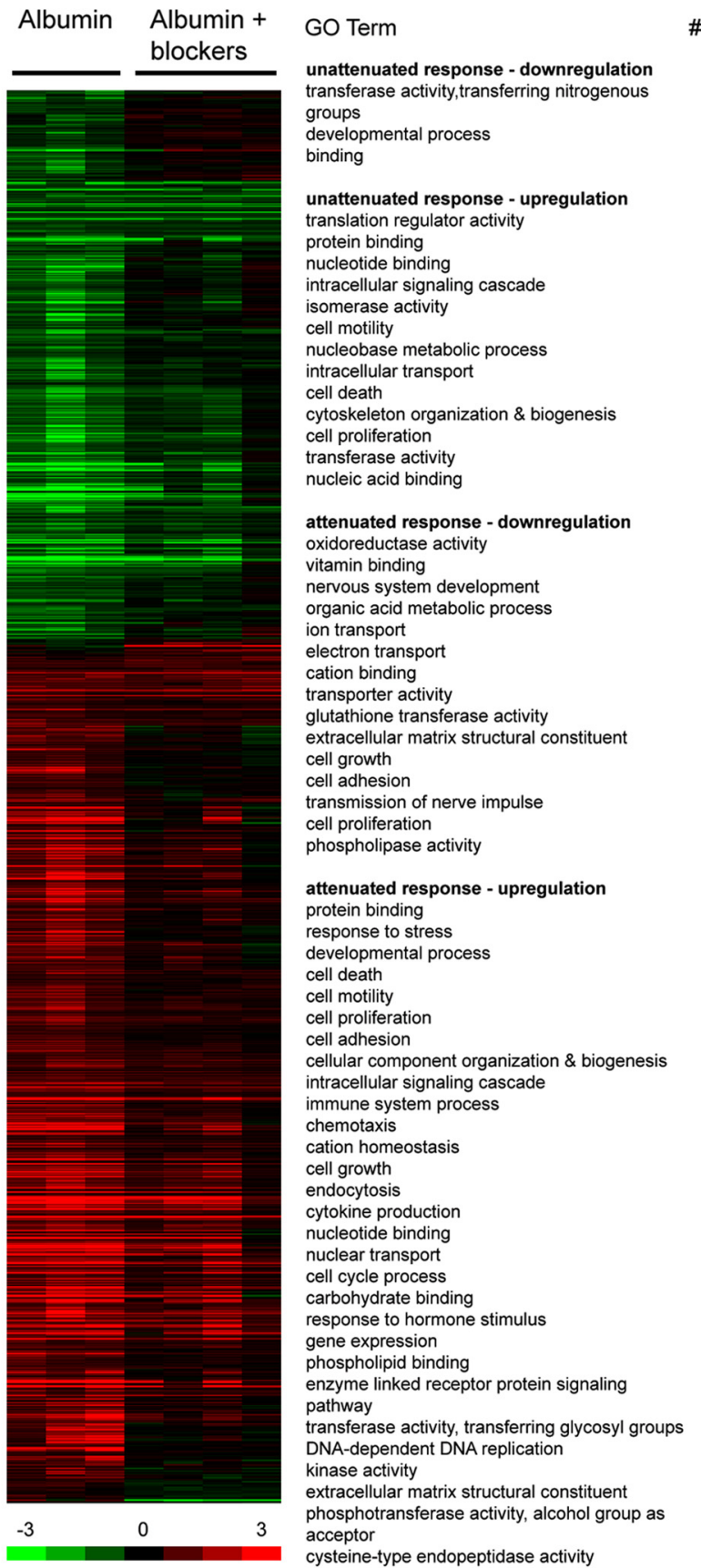

\begin{tabular}{|c|c|c|c|c|c|}
\hline \# genes & $\%$ & p-value & & & \\
\hline & & & Gene symbol & folc & change \\
\hline 3 & 3.2 & 5.3E-03 & & albumin & albumi \\
\hline 16 & 17.0 & 4.1E-02 & TGF- $\beta$ siana & & + blocke \\
\hline 41 & 43.6 & $1.3 \mathrm{E}-02$ & & & \\
\hline & & & Spp1 & 85.4 & 10.8 \\
\hline $\begin{array}{l}9 \\
62\end{array}$ & $\begin{array}{c}5.6 \\
38.5\end{array}$ & $\begin{array}{l}7.8 \mathrm{E}-07 \\
4.7 \mathrm{E}-06\end{array}$ & PAl-1 & 6.4 & 1.4 \\
\hline 29 & 18.0 & 1.6E-04 & Stat3 & 6.0 & 1.3 \\
\hline 23 & 14.3 & 2.3E-04 & Fos & 4.7 & 1.0 \\
\hline 6 & 3.7 & $2.2 \mathrm{E}-03$ & Tafb2 & 2.9 & 1.3 \\
\hline 9 & 5.6 & $1.0 \mathrm{E}-02$ & IgIDL & 2.9 & 1.0 \\
\hline 3 & 1.9 & 1.1E-02 & Tgif & 2.7 & 1.6 \\
\hline 12 & 7.5 & $1.2 \mathrm{E}-02$ & Smad1 & 2.7 & 1.5 \\
\hline 12 & 7.5 & 2.1E-02 & Jun & 2.3 & 1.0 \\
\hline 9 & 5.6 & 2.4E-02 & $\mathrm{Bmp} 6$ & -2.5 & -1.2 \\
\hline 12 & 7.5 & $2.5 \mathrm{E}-02$ & & & \\
\hline 20 & 12.4 & 3.6E-02 & & & \\
\hline 27 & 16.8 & $4.8 \mathrm{E}-02$ & & & \\
\hline & & & Immune res & & \\
\hline 28 & 8.6 & $9.5 \mathrm{E}-06$ & & & \\
\hline 8 & 2.5 & $4.9 \mathrm{E}-04$ & $\mathrm{Ccl} 2$ & 356.2 & 30.5 \\
\hline 23 & 7.0 & 6.8E-04 & Ccl7 & 59.2 & 4.2 \\
\hline 18 & 5.5 & $9.0 \mathrm{E}-04$ & CD14 & 36.3 & 3.4 \\
\hline 22 & 6.7 & $9.2 \mathrm{E}-04$ & Tnfrsf12a & 29.2 & 5.7 \\
\hline 15 & 4.6 & 1.8E-03 & CD44 & 28.6 & 5.9 \\
\hline 49 & 15.0 & 2.1E-03 & & & \\
\hline 29 & 8.9 & 2.4E-03 & Gal & 9.4 & 1.8 \\
\hline $\begin{array}{l}4 \\
5\end{array}$ & $\begin{array}{l}1.2 \\
1.5\end{array}$ & $\begin{array}{l}6.7 \mathrm{E}-03 \\
1.3 \mathrm{E}-02\end{array}$ & C5r1 & 5.2 & 1.2 \\
\hline $\begin{array}{l}5 \\
7\end{array}$ & $\begin{array}{l}1.5 \\
2.1\end{array}$ & $\begin{array}{l}1.3 \mathrm{E}-\mathrm{U} 2 \\
1.7 \mathrm{E}-02\end{array}$ & Il1rap & 4.9 & 1.0 \\
\hline 15 & 4.6 & $2.8 \mathrm{E}-02$ & $\| 1 \mathrm{r} 2$ & 2.1 & 1.1 \\
\hline 12 & 3.7 & 4.0E-02 & $\mathrm{Fn} 1$ & 1.7 & 1.1 \\
\hline 17 & 5.2 & 4.1E-02 & & & \\
\hline
\end{tabular}

\section{Ion and cellular transport}

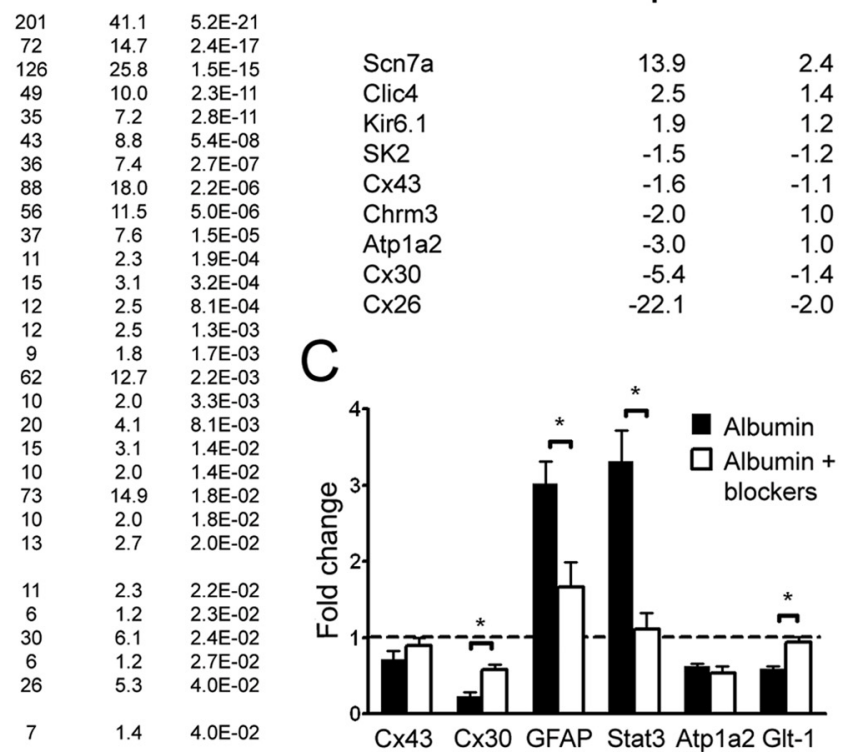

Figure 6. Blocking TGF- $\beta$ signaling prevents albumin-induced gene expression. $A$, Genomic expression analysis after treatment with albumin or albumin plus TGF- $\beta$ receptor blockers. SAM was performed with an FDR threshold of $9.2 \%$, and these genes are represented on the heat map. Gene ontology analysis was performed with DAVID for genes showing an attenuated [(albumin $\log _{2}$ ratio) - (albumin + blocker $\log _{2}$ ratio) $>0.5$ ] or unattenuated response after treatment with albumin plus TGF- $\beta$ receptor blockers compared with albumin treatment (see Materials and Methods). $\boldsymbol{B}$, Fold changes for specific genes from G0 analysis. C, qPCR analysis for selected genes after albumin $(n=3)$ or albumin plus TGF- $\beta$ receptor blockers $(n=4)$. Error bars indicate SEM, and asterisks indicate $p<0.05$.

Interestingly, TGF- $\beta 1$ is generally considered to have a protective function. Previous studies have demonstrated the ability of TGF- $\beta 1$ to prevent glutamate neurotoxicity in vitro and protect against ischemic injury in vivo (Prehn et al., 1993; Henrich-Noack et al., 1996; Ruocco et al., 1999). However, studies have also suggested TGF- $\beta 1$ may not always be neuroprotective. Transgenic mice overexpressing TGF- $\beta 1$ specifically in astrocytes (Wyss-Coray et al., 1995) developed seizures (along with overproduction of extracellular matrix components, severe communicating hydrocephalus, motor incoor- dination, and early runting). Furthermore, a recent study has demonstrated that blockade of TGF- $\beta-$ Smad $2 / 3$ signaling in peripheral macrophages in a mouse model for Alzheimer's disease results in marked attenuation of cerebrovascular-amyloid deposits (Town et al., 2008). These studies, along with our work, illustrate the complexity and importance of TGF- $\beta$ signaling in neurological diseases. Additional work is needed to elucidate the mechanisms responsible for the protective and detrimental effects of TGF- $\beta$ signaling.

Other significant findings from our microarray results include 
the early upregulation of genes involved in inflammatory processes and the delayed downregulation of genes involved in neuronal processes including synaptic transmission and ion transport. Features of CNS inflammation, such as glial and complement activation, cytokine production, and adhesion protein expression, were all present in our array data. Upregulation of genes involved in activation of the NF- $\kappa \mathrm{B}$ pathway and complement cascade reflects a significant innate immune response. In recent years, several studies have shed light on the importance of inflammatory processes in epilepsy. Both NF- $\kappa$ B pathway activation and complement activation have been reported in various epilepsy animal models (Rozovsky et al., 1994; Rong and Baudry, 1996; Lubin et al., 2007; van Vliet et al., 2007), as well as the involvement of other immune response genes including Il6 (Balosso et al., 2008), Ccl2 (Calvo et al., 1996; Manley et al., 2007), Stat3 (Choi et al., 2003), and Fn1 (Hoffman and Johnston, 1998). A study by Rizzi et al. (2003), where status epilepticus (SE) was induced with kainic acid, found cytokines to be causally involved in the SE-induced neuronal damage, as cytokine synthesis preceded hippocampal neuronal injury, and this injury only occurred when cytokines were produced (Rizzi et al., 2003).

Some immune-related genes have also been shown to play a role in neuronal functions. Cytokines such as interleukin- $1 \beta$ (Il1b) and tumor necrosis factor (TNF) have been shown to increase neuronal excitability. $I l 1 b$ mediates increased neuronal glutamate release (Casamenti et al., 1999), induces phosphorylation of the NMDA NR2B subunit (Viviani et al., 2003; Balosso et al., 2008), and prevents glutamate uptake by astrocytes (Hu et al., 2000). TNF promotes recruitment of AMPA receptors lacking the Glur2 subunit to the neuronal membrane leading to increased calcium influx and also promotes endocytosis of $\mathrm{GABA}_{\mathrm{A}}$ receptors (Beattie et al., 2002; Stellwagen et al., 2005; Leonoudakis et al., 2008). An upregulation of TNF was observed in our arrays, indicating it may be involved in increasing neuronal excitability during epileptogenesis in addition to its immunerelated functions. Another immune-related protein with a possible nonimmune function after injury is $\mathrm{Clq}$, the first component of the classical complement cascade. $\mathrm{Clq}$ has recently been shown to play a role in synapse elimination during development and in neurodegeneration (Stevens et al., 2007). Upregulation of several C1q subcomponents in our arrays may be associated with synaptic remodeling and neuronal loss after the generation of the epileptic focus (Ivens et al., 2007).

An imbalance of excitatory and inhibitory transmission resulting in increased network excitability is a feature of most epilepsy models. In our study, several $\mathrm{GABA}_{\mathrm{A}}$ receptor subunits were downregulated, whereas ionotropic glutamate receptor subunits were upregulated. Genes involved in glutamate transport (Glt-1) as well as voltage-gated ion channels were also downregulated. These changes, appearing in the middle-late time points, predict an increase in network excitability. These results are also consistent with a previous microarray study examining gene expression changes during epileptogenesis after electrically induced SE (van Vliet et al., 2007), which found downregulation of $\mathrm{GABA}_{\mathrm{A}}$ and NMDA receptor subunits.

Our initial findings showing albumin uptake by astrocytes (Ivens et al., 2007) raised the hypothesis that an early glial response precedes the development of abnormal neuronal activity. This hypothesis is reinforced by our microarray data. Glial cells are responsible for the homeostasis of the extracellular environment (i.e., uptake of glutamate and potassium) under normal conditions and for the initiation of inflammatory processes in the CNS when activated after injury. Our results support various studies that have implicated a role for these cells in epileptic activity (Tian et al., 2005; Wetherington et al., 2008). Importantly, the early astrocytic response, before epileptic activity is observed, further strengthens the putative role of these cells in the epileptogenic process itself. The downregulation of the astrocytic glutamate transporter, Glt-1, the inward rectifier potassium channels (Kir 4.1) and connexins Cx26, Cx30, and Cx43, all predict impaired buffering of glutamate and potassium, which in turn will enhance local neuronal excitability. The upregulation of the transcription factor Stat3 predicts astrocytic differentiation (Morita et al., 1995) and transformation (Choi et al., 2003). In addition, upregulation of GFAP and vimentin provide evidence for reactive gliosis found in many epilepsy models, which is characterized by hypertrophy and increased intermediate filament expression (Wetherington et al., 2008). Overall, our microarray data suggest a pronounced immediate glial response followed by a later neuronal response. It remains to be determined whether our treatments induce the release of mediators from astrocytes that in turn activate transcription in neurons as well as in other cell types such as microglia and endothelial cells.

Although many of the molecular changes revealed by our microarray study are shared with different epilepsy models, our study is the first to demonstrate that these changes, after direct vascular injury (i.e., BBB breakdown), are associated with brain exposure to serum albumin and are mediated via the TGF- $\beta$ signaling pathway. Indeed, using TGF- $\beta$ pathway blockers, we were able to not only block the transcriptional response after albumin exposure in vivo but also the development of epileptiform activity. Combined, these results present the TGF- $\beta$ pathway as a novel therapeutic tool for preventing injury-related epileptogenesis.

\section{References}

Abbott NJ, Rönnbäck L, Hansson E (2006) Astrocyte-endothelial interactions at the blood-brain barrier. Nat Rev Neurosci 7:41-53.

Balosso S, Maroso M, Sanchez-Alavez M, Ravizza T, Frasca A, Bartfai T, Vezzani A (2008) A novel non-transcriptional pathway mediates the proconvulsive effects of interleukin-1beta. Brain 131:3256-3265.

Beattie EC, Stellwagen D, Morishita W, Bresnahan JC, Ha BK, Von Zastrow M, Beattie MS, Malenka RC (2002) Control of synaptic strength by glial TNFalpha. Science 295:2282-2285

Calvo CF, Yoshimura T, Gelman M, Mallat M (1996) Production of monocyte chemotactic protein-1 by rat brain macrophages. Eur J Neurosci 8:1725-1734.

Casamenti F, Prosperi C, Scali C, Giovannelli L, Colivicchi MA, FaussonePellegrini MS, Pepeu G (1999) Interleukin-1beta activates forebrain glial cells and increases nitric oxide production and cortical glutamate and GABA release in vivo: implications for Alzheimer's disease. Neuroscience 91:831-842.

Choi JS, Kim SY, Park HJ, Cha JH, Choi YS, Kang JE, Chung JW, Chun MH, Lee MY (2003) Upregulation of gp130 and differential activation of STAT and p42/44 MAPK in the rat hippocampus following kainic acidinduced seizures. Brain Res Mol Brain Res 119:10-18.

Connors BW, Gutnick MJ, Prince DA (1982) Electrophysiological properties of neocortical neurons in vitro. J Neurophysiol 48:1302-1320.

Cornford EM (1999) Epilepsy and the blood brain barrier: endothelial cell responses to seizures. Adv Neurol 79:845-862.

Cornford EM, Oldendorf WH (1986) Epilepsy and the blood-brain barrier. Adv Neurol 44:787-812.

Dennis G Jr, Sherman BT, Hosack DA, Yang J, Gao W, Lane HC, Lempicki RA (2003) DAVID: database for annotation, visualization, and integrated discovery. Genome Biol 4:P3.

Eisen MB, Spellman PT, Brown PO, Botstein D (1998) Cluster analysis and display of genome-wide expression patterns. Proc Natl Acad Sci U S A 95:14863-14868.

Gutnick MJ, Connors BW, Prince DA (1982) Mechanisms of neocortical epileptogenesis in vitro. J Neurophysiol 48:1321-1335.

Henrich-Noack P, Prehn JH, Krieglstein J (1996) TGF-beta 1 protects hip- 
pocampal neurons against degeneration caused by transient global ischemia. Dose-response relationship and potential neuroprotective mechanisms. Stroke 27:1609-1614; discussion 1615.

Hoffman DA, Johnston D (1998) Downregulation of transient $\mathrm{K}^{+}$channels in dendrites of hippocampal CA1 pyramidal neurons by activation of PKA and PKC. J Neurosci 18:3521-3528.

Hu S, Sheng WS, Ehrlich LC, Peterson PK, Chao CC (2000) Cytokine effects on glutamate uptake by human astrocytes. Neuroimmunomodulation 7:153-159.

Ivens S, Kaufer D, Flores LP, Bechmann I, Zumsteg D, Tomkins O, Seiffert E, Heinemann U, Friedman A (2007) TGF-beta receptor-mediated albumin uptake into astrocytes is involved in neocortical epileptogenesis. Brain 130:535-547.

Kasantikul V, Brown WJ, Oldendorf WH, Crandall PC (1983) Ultrastructural parameters of limbic microvasculature in human psychomotor epilepsy. Clin Neuropathol 2:171-178.

Leonoudakis D, Zhao P, Beattie EC (2008) Rapid tumor necrosis factor $\alpha$-induced exocytosis of glutamate receptor 2-lacking AMPA receptors to extrasynaptic plasma membrane potentiates excitotoxicity. J Neurosci 28:2119-2130.

Lubin FD, Ren Y, Xu X, Anderson AE (2007) Nuclear factor-kappa B regulates seizure threshold and gene transcription following convulsant stimulation. J Neurochem 103:1381-1395.

Manley NC, Bertrand AA, Kinney KS, Hing TC, Sapolsky RM (2007) Characterization of monocyte chemoattractant protein-1 expression following a kainate model of status epilepticus. Brain Res 1182:138-143.

Marchi N, Angelov L, Masaryk T, Fazio V, Granata T, Hernandez N, Hallene K, Diglaw T, Franic L, Najm I, Janigro D (2007) Seizure-promoting effect of blood-brain barrier disruption. Epilepsia 48:732-742.

Morita H, Yanagisawa N, Nakajima T, Shimizu M, Hirabayashi H, Okudera H, Nohara M, Midorikawa Y, Mimura S (1995) Sarin poisoning in Matsumoto, Japan. Lancet 346:290-293.

Neuwelt EA (2004) Mechanisms of disease: the blood-brain barrier. Neurosurgery 54:131-140; discussion 141-132.

Oby E, Janigro D (2006) The blood-brain barrier and epilepsy. Epilepsia 47:1761-1774.

Pavlovsky L, Browne RO, Friedman A (2003) Pyridostigmine enhances glutamatergic transmission in hippocampal CA1 neurons. ExpNeurol 179:181-187.

Pfaffl MW (2001) A new mathematical model for relative quantification in real-time RT-PCR. Nucleic Acids Res 29:e45.

Prehn JH, Backhauss C, Krieglstein J (1993) Transforming growth factorbeta 1 prevents glutamate neurotoxicity in rat neocortical cultures and protects mouse neocortex from ischemic injury in vivo. J Cereb Blood Flow Metab 13:521-525.

Rigau V, Morin M, Rousset MC, de Bock F, Lebrun A, Coubes P, Picot MC, Baldy-Moulinier M, Bockaert J, Crespel A, Lerner-Natoli M (2007) Angiogenesis is associated with blood-brain barrier permeability in temporal lobe epilepsy. Brain 130:1942-1956.

Rizzi M, Perego C, Aliprandi M, Richichi C, Ravizza T, Colella D, Velískǒvá J, Moshé SL, De Simoni MG, Vezzani A (2003) Glia activation and cytokine increase in rat hippocampus by kainic acid-induced status epilepticus during postnatal development. Neurobiol Dis 14:494-503.

Rong Y, Baudry M (1996) Seizure activity results in a rapid induction of nuclear factor-kappa B in adult but not juvenile rat limbic structures. J Neurochem 67:662-668.
Rozovsky I, Morgan TE, Willoughby DA, Dugichi-Djordjevich MM, Pasinetti GM, Johnson SA, Finch CE (1994) Selective expression of clusterin (SGP-2) and complement $\mathrm{ClqB}$ and $\mathrm{C} 4$ during responses to neurotoxins in vivo and in vitro. Neuroscience 62:741-758.

Ruocco A, Nicole O, Docagne F, Ali C, Chazalviel L, Komesli S, Yablonsky F, Roussel S, MacKenzie ET, Vivien D, Buisson A (1999) A transforming growth factor-beta antagonist unmasks the neuroprotective role of this endogenous cytokine in excitotoxic and ischemic brain injury. J Cereb Blood Flow Metab 19:1345-1353.

Salomonis N, Hanspers K, Zambon AC, Vranizan K, Lawlor SC, Dahlquist KD, Doniger SW, Stuart J, Conklin BR, Pico AR (2007) GenMAPP 2: new features and resources for pathway analysis. BMC Bioinformatics 8:217.

Seiffert E, Dreier JP, Ivens S, Bechmann I, Tomkins O, Heinemann U, Friedman A (2004) Lasting blood-brain barrier disruption induces epileptic focus in the rat somatosensory cortex. J Neurosci 24:7829-7836.

Siddiqui SS, Siddiqui ZK, Malik AB (2004) Albumin endocytosis in endothelial cells induces TGF-beta receptor II signaling. Am J Physiol Lung Cell Mol Physiol 286:L1016-L1026.

Stellwagen D, Beattie EC, Seo JY, Malenka RC (2005) Differential regulation of AMPA receptor and GABA receptor trafficking by tumor necrosis factor- $\alpha$. J Neurosci 25:3219-3228.

Stevens B, Allen NJ, Vazquez LE, Howell GR, Christopherson KS, Nouri N, Micheva KD, Mehalow AK, Huberman AD, Stafford B, Sher A, Litke AM, Lambris JD, Smith SJ, John SW, Barres BA (2007) The classical complement cascade mediates CNS synapse elimination. Cell 131:1164-1178.

Tian GF, Azmi H, Takano T, Xu Q, Peng W, Lin J, Oberheim N, Lou N, Wang X, Zielke HR, Kang J, Nedergaard M (2005) An astrocytic basis of epilepsy. Nat Med 11:973-981.

Tomkins O, Kaufer D, Korn A, Shelef I, Golan H, Reichenthal E, Soreq H, Friedman A (2001) Frequent blood-brain barrier disruption in the human cerebral cortex. Cell Mol Neurobiol 21:675-691.

Town T, Laouar Y, Pittenger C, Mori T, Szekely CA, Tan J, Duman RS, Flavell RA (2008) Blocking TGF-beta-Smad2/3 innate immune signaling mitigates Alzheimer-like pathology. Nat Med 14:681-687.

van Vliet EA, da Costa Araújo S, Redeker S, van Schaik R, Aronica E, Gorter JA (2007) Blood-brain barrier leakage may lead to progression of temporal lobe epilepsy. Brain 130:521-534.

Viviani B, Bartesaghi S, Gardoni F, Vezzani A, Behrens MM, Bartfai T, Binaglia M, Corsini E, Di Luca M, Galli CL, Marinovich M (2003) Interleukin- $1 \beta$ enhances NMDA receptor-mediated intracellular calcium increase through activation of the Src family of kinases. J Neurosci 23:8692-8700.

Wetherington J, Serrano G, Dingledine R (2008) Astrocytes in the epileptic brain. Neuron 58:168-178.

Wu Z, Irizarry R, Gentleman R, Murillo FM, Spencer F (2004) A modelbased background adjustment for oligonucleotide expression arrays. J Am Stat Assoc 99:909-917.

Wyss-Coray T, Feng L, Masliah E, Ruppe MD, Lee HS, Toggas SM, Rockenstein EM, Mucke L (1995) Increased central nervous system production of extracellular matrix components and development of hydrocephalus in transgenic mice overexpressing transforming growth factor-beta 1. Am J Pathol 147:53-67.

Zlokovic BV (2008) New therapeutic targets in the neurovascular pathway in Alzheimer's disease. Neurotherapeutics 5:409-414. 